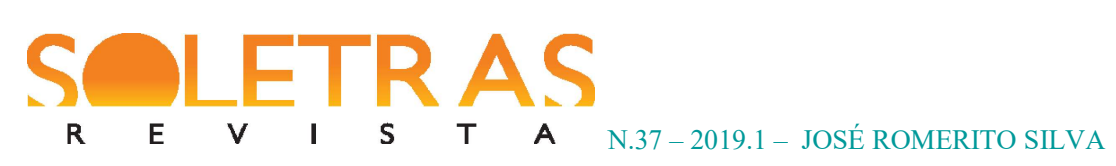

\title{
Intensificação do verbo e mudança construcional
}

José Romerito Silva ${ }^{1}$

Resumo: Neste trabalho, temos como foco central a intensificação de verbos com super. Partimos da hipótese de que se trata de um fenômeno de mudança construcional. Temos como objetivo mostrar que essa forma de intensificar o verbo difere do modo convencional - em que super é prefixo participante da formação lexical do verbo -, configurando-se, portanto, uma nova microconstrução no português brasileiro contemporâneo. Para tanto, valemo-nos do aparato teórico-metodológico da Linguística Funcional Centrada no Uso. Como material de análise, utlizamos textos de gêneros variados nas modalidades falada e escrita. Investigações preliminares apontam que a intensificação verbal com super parece ainda se limitar à fala espontânea pouco monitorada ou à escrita mais próxima dessa forma de oralidade.

Palavras-chave: Intensificação do verbo. Linguística Funcional Centrada no Uso. Mudança construcional.

\section{Introdução}

Embora muito recorrente na comunicação oral e na escrita, o grau do verbo tem sido um fenômeno quase que completamente ignorado nos estudos linguísticos. Na descrição do português, as exceções são Almeida (1999), ao tratar de verbos aumentativos e verbos diminutivos; Lopes (2003), ao focalizar os verbos intensivos; e Silva (2008, 2015), que, abordando a intensificação, incluiu o grau do verbo em suas análises.

A esse respeito, além dos pouquíssimos casos já consagrados de intensificação verbal com o prefixo super, como superlotar, superfaturar e superestimar, por exemplo, observamos que, mais recentemente, têm-se mostrado bastante produtivos e frequentes usos de verbos intensificados com super em ocorrências como super quero voltar, super me identifiquei, super vale à pena, entre outras. Nessas formações, em vez de o verbo ser intensificado com advérbios como muito, bastante, demais e similares - ou seja, conforme o padrão convencional -, intensifica-se com super, em que este assume propriedades de advérbio. Esses usos revelam um novo paradigma para a graduação do verbo no português brasileiro

\footnotetext{
${ }^{1}$ Professor Associado 2 da Universidade Federal do Rio Grande do Norte (UFRN). É vinculado à Escola de Ciências e Tecnologia (ECT/UFRN), ministrando disciplinas na área de Práticas de Leitura e Escrita, e ao Programa de Pós-graduação em Estudos da Linguagem (PpgEL/UFRN), atuando no desenvolvimento e na orientação de pesquisas em Linguística Funcional Centrada no Uso junto ao grupo de estudos Discurso \& Gramática.
} 


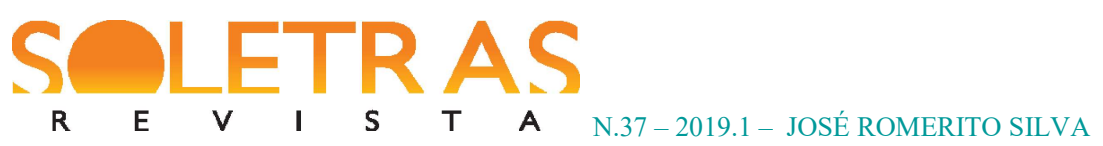

(PB) contemporâneo, semelhantemente ao que ocorre em casos de intensificação de adjetivos, advérbios e locuções adjetivas/adverbiais com super, como super bem feito, super maleducado, super à vontade, super em forma, em que esse elemento intensivo parece concorrer com intensificadores canônicos como muito ou bastante, discutidos em Silva (2001).

Em vista dessas constatações, abordamos aqui a intensificação verbal com super na perspectiva da mudança construcional, conforme vem sendo tratada pela Linguística Funcional Centrada no Uso. Para tanto, recorremos a autores como Goldberg (1995, 2003), Croft (2001), Traugott \& Dasher (2002), Himmelmann (2004), Traugott (2009), Bybee (2010), Traugott \& Trousdale (2010, 2013), entre outros.

Neste ponto, cabe levantar as seguintes questões: quais as distinções entre o novo padrão de intensificação verbal com super e o que tem esse intensificador como prefixo?; como se configura a construção de intensidade verbal com super em termos semânticos, sintáticos e morfológicos?; por que esse novo padrão de intensificação do verbo deve ser visto como um caso de mudança construcional?; que fator(es) está(ão) implicado(s) no recrutamento de super para a formação desse novo padrão de intensificação verbal?

Para a análise dos dados, recorremos a 30 (trinta) excertos textuais coletados da internet. Trata-se de textos provindos de posts - comentários de leitores, reclamações de clientes, fofocas sobre celebridades, dicas (de moda, beleza, saúde etc.) -, os quais foram publicados em blogs, no twitter ou no facebook e em demais sites. Nesses excertos, encontramos 37 ocorrências de verbos intensificados por super, sendo essas ocorrências representantes de 33 verbos distintos.

Dado o seu caráter informal, revelando baixo monitoramento, esses textos aproximam-se da modalidade falada distensa. Cabe frisar, ainda, que contextos discursivos como esses são um terreno propício para o florescimento de experimentações inovadoras na língua, em razão do teor de (inter)subjetividade que costuma orientar a interação comunicativa.

Este trabalho está dividido nas seguintes partes: além desta seção - introdutória -, na sequência, apresentamos o quadro teórico-metodológico; depois, analisamos o objeto de estudo em foco; e, por último, fazemos as considerações finais.

\section{Enquadre teórico-metodológico}


Linguística Funcional Centrada no Uso (LFCU) é o termo cunhado no Brasil pelo grupo de estudos Discurso \& Gramática como equivalente ao que mais se conhece na literatura de língua inglesa como Usage-based Linguistics. A LFCU caracteriza-se por procurar combinar a tradição funcionalista norte-americana com pressupostos e ferramentas analíticas da Gramática de Construções, principalmente na linha de Goldberg (1995, 2003, 2006) e de Croft (2001).

Entre os princípios fundamentais que sustentam a abordagem da LFCU, estão os seguintes: a língua é um sistema adaptativo complexo, forjada no/pelo uso, configurando-se em uma rede taxonômica de construções hierarquizadas e interconectadas por relações de natureza diversa; a unidade básica da língua é a construção, entendida como pareamento de forma e função; léxico e gramática se constituem num continuum; o estudo da língua deve levar em conta fatores cognitivos, discursivos e sociointeracionais implicados em seu uso e motivadores de sua estrutura (KEMMER; BARLOW, 2002; FURTADO DA CUNHA, BISPO; SILVA, 2013).

Segundo Croft (2001), a construção compreende o elo simbólico entre o polo da forma, constituído de propriedades fonológicas, morfológicas e sintáticas, e o da função, constituído de propriedades semânticas, discursivas e pragmáticas. Sob a ótica da LFCU, embora as propriedades de ambos os polos se interpenetrem e se influenciem mutuamente em uma dada construção, o polo da função parece ter predominância sobre o da forma, dada a pressão motivadora que aquele exerce sobre a configuração deste (FURTADO DA CUNHA; SILVA; BISPO, 2016). A seguir, reproduzimos a arquitetura construcional formulada por Croft.

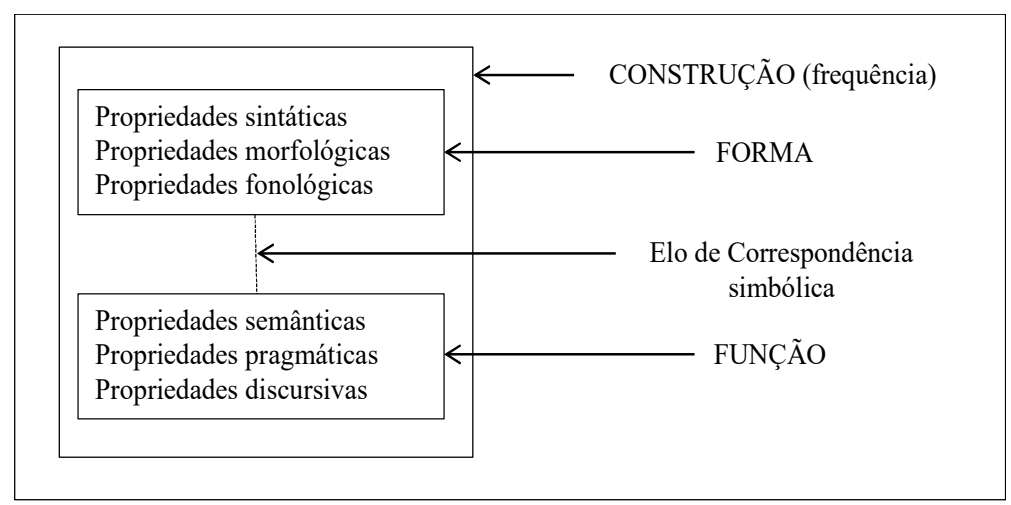

Quadro 1 - Arquitetura construcional.

Fonte - Adaptado de Croft (2001). 


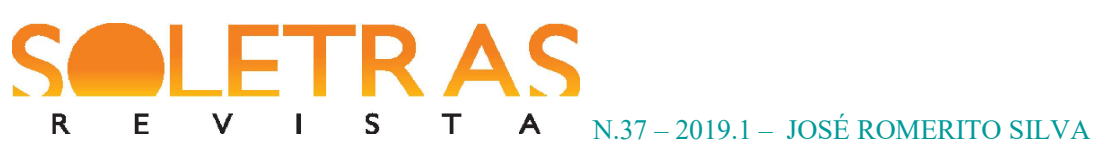

$\mathrm{Na}$ acepção de Goldgerg (2003), a construção pode consistir desde um morfema simples a uma oração complexa (período composto). Ainda conforme a autora, uma construção pode ser completamente especificada (idiossincrática), tal como Era uma vez; parcialmente preenchida, do tipo Tanto X como $Y$; ou totalmente aberta (esquemática), como a formação morfológica Base + Suf ou a sintática $S V O$.

A esse respeito, Fried (2015) postula uma outra categoria intermediária de construção, caracterizada por ser totalmente preenchida e parcialmente flexível. Ilustra essa categoria, em português, a construção fazer das tripas coração, na qual o primeiro elemento (o verbo) se flexiona normalmente.

Conforme Traugott \& Trousdale (2013), uma construção pode ser aferida em referência ao grau de esquematicidade, de produtividade e de composicionalidade que ela exibe. Quanto mais geral e abstrata, mais esquemática e aberta é a construção, o que pode levá-la a se tornar mais produtiva em razão de sua suscetibilidade de licenciar outras construções aparentadas pelo conteúdo e/ou pela forma. Nesse sentido, certo(s) slot(s) dessa construção pode(m) passar a ser preenchido(s) por nova(s) categoria(s), o que implica aumento de sua classe hospedeira, conforme entendido por Himmelmann (2004). Já a composicionalidade de uma construção tem a ver com o grau de analisabilidade dos seus componentes, ou seja, quanto mais analisável é a construção em termos de seus elementos individuais, mais composicional ela é; quanto menos analisável, mais fechada/idiossincrática.

Segundo Goldberg (1995), a rede construcional se constitui por relações (links) de herança ${ }^{2}$ entre uma construção e suas diferentes instanciações bem como entre construções distintas. Esse postulado parte do princípio de que existe uma construção mais central/básica, que funciona como uma construção motivadora e, sancionadas por ela, outras podem ser criadas a partir desses links de herança. Para a autora, existem quatro tipos de relações que podem ser estabelecidas: polissemia, metáfora, subparte e instanciação.

O link de herança por polissemia revela as relações semânticas entre uma construção e suas extensões de sentido. Esse tipo de link pode ser ilustrado, por exemplo, com as construções ditransitivas (1) Jonas deu um presente à namorada e (2) Josias prometeu uma boa surpresa a Célia. Em (1), um agente causa a transferência de um objeto para um

2 Não estamos considerando aqui a distinção apresentada em Traugott \& Trousdale (2013) entre links relacionais e links de herança. 


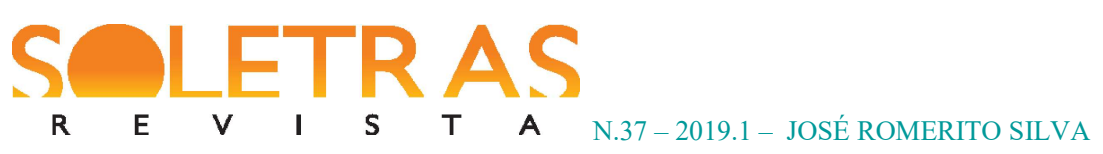

recipiente. Essa construção pode ser representada pela estrutura conceitual X CAUSA Y RECEBER Z, sendo considerada a construção mais básica por apresentar o sentido mais central. Já em (2), tem-se a mesma estrutura sintática da oração anterior, mas ela é semanticamente distinta pelo fato de a promessa ser uma "transferência" abstrata (que pode ou não se cumprir), assim como uma boa surpresa é o objeto abstrato "transferido".

A extensão de sentido de uma construção também pode se dar por mapeamento metafórico. Assim, por exemplo, na oração (3) O cantor deu uma banana para quem o xingava,embora dar seja um verbo que denota transferência de posse, nesse caso, ele tem sentido metafórico, visto não ser possível, de fato, transferir o objeto banana, que também é metafórico.

A relação por subparte ocorre quando uma construção apresenta uma configuração parcial de outra construção, existindo independentemente desta. Um exemplo disso é a relação entre a construção resultativa, como (4) $O$ sol derreteu o gelo, e a resultativa intransitiva, como (5) O gelo derreteu. A primeira pode ser representada pela estrutura semântica CAUSAR TORNAR-SE, e a segunda apresenta apenas TORNAR-SE em sua estrutura conceitual. As duas construções são integradas pelo verbo derreter, porém (4) é uma construção de dois argumentos, com os papéis temáticos causativo (o sol) e paciente (o gelo); (5), por sua vez, é uma construção monoargumental, que perfila apenas o sujeito paciente (o gelo).

O link de herança por intanciação se mostra quando uma dada construção constitui-se num caso especial/particular de outra construção. Um exemplo que pode ilustrar esse tipo de herança é o que se dá com (6) O menino espirrou catarro na comida, em que espirrar, convencionalmente usado como verbo intransitivo, nessa oração, comporta-se como verbo ditransitivo causativo. Nesse caso, (6) representa uma extensão de sentido da construção ditransitiva central de movimento causado (X CAUSA Y MOVER-SE PARA Z), tornando-se, portanto, uma instanciação especial desta.

Ainda segundo Goldberg (1995) e Traugott \& Trousdale (2013), uma construção pode herdar propriedades de mais de uma construção. Nesse caso, trata-se de links de herança múltipla. Esse tipo de relação pode ser exemplificado com o construto (7) Que livro foi adotado pelo professor?, o qual instancia uma construção interrogativa na voz passiva. Sendo assim, essa construção, sob a ótica dos autores mencionados, herda propriedades tanto da construção interrogativa como da passiva. 
Esses links por meio dos quais um conjunto de construções se interconecta são responsáveis pela formação de uma rede hierarquizada, em que instâncias de construções de nível inferior e mais especificadas se associam e herdam propriedades de construções superordenadas mais esquemáticas e/ou menos especificadas (GOLDBERG, 1995). Para Traugott \& Trousdale (2013), a construção matriz de nível superior e mais esquemática constitui o esquema construcional básico. Este, dependendo de seu grau de produtividade, sanciona uma variedade de subesquemas subordenados, os quais podem inseminar um leque de microconstruções de nível mais baixo, sendo estas instanciadas por realizações efetivas no uso comunicativo.

Essa rede hierárquica corresponde ao que Traugott (2009) já havia formulado como macroconstrução (esquema básico superordenado), mesoconstrução (subesquema de nível intermediário), microconstrução (instanciação de nível inferior), construto (instância de uso). Tal hierarquia construcional pode ser representada conforme se mostra a seguir:

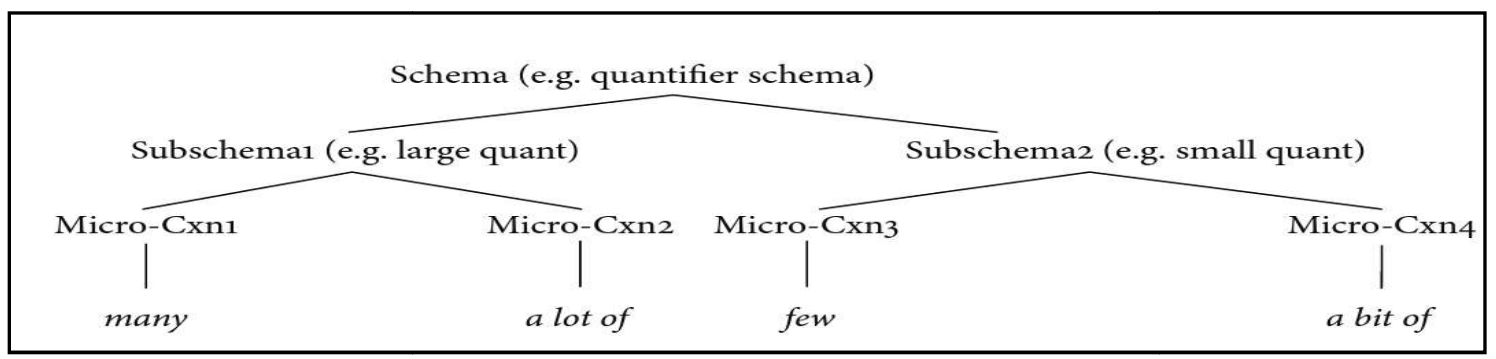

Quadro 2 - Relações hierárquicas da rede construcional.

Fonte - Traugott \& Trousdale (2013, p. 16).

Ainda em relação a essa rede hierárquica construcional, vale ressaltar que determinadas microconstruções e/ou subesquemas podem apresentar paridade formal, porém divergem no(s) plano(s) semântico e/ou pragmático. Quanto a isso o Princípio da NãoSinonímia, formulado por Goldberg (1995, p. 67), estabelece que "se duas construções são sintaticamente distintas, tais construções devem ser também distintas semântica ou pragmaticamente" [tradução nossa] $]^{3}$. Por esse princípio, o mesmo significado (semântico e pragmático) não pode ser expresso por duas formas diferentes, embora uma mesma forma possa expressar significados diversos, tal como se mostra na rede.

Esse princípio pode ser correlacionado ao que Bolinger ([1968] apud GOLDBERG,

3"If two constructions are syntactically distinct, they must be semantically or pragmatically distinct." 
1995, p. 4) já formulara em outros termos: "uma diferença na forma sempre traduz diferença no significado" [tradução nossa] ${ }^{4}$. Assim, podemos concluir que diferença de forma envolve, de algum modo e em alguma medida, divergência de função semântica e/ou pragmática (cf. HAIMAN, 1983; GIVÓN, 1985).

No tocante à mudança linguística, Traugott \& Trousdale (2013) postulam as noções de mudança construcional e construcionalização. A primeira diz respeito a mudanças internas à construção, as quais ocorrem no domínio da forma ou no da função; a segunda refere-se a mudanças em ambos os domínios, resultando na criação de um novo nó na rede, ou seja, de uma nova construção, que pode ou não se tornar esquemática. O Quadro 3, a seguir, resume e ilustra essas noções.

\begin{tabular}{|c|c|c|c|}
\hline Fenômeno & Forma & Função & Exemplificação \\
\hline $\begin{array}{c}\text { Mudança } \\
\text { construcional }\end{array}$ & nova & velha & Não pós-verbal \\
\cline { 2 - 4 } & velha & nova & Aquele intensificador \\
\hline Construcionalização & nova & nova & Ir auxiliar de futuro \\
\hline
\end{tabular}

Quadro 3 - Mudança linguística conforme Traugott \& Trousdale (2013)

Fonte- Autoria própria

Segundo esse modelo, a mudança construcional é gradiente e vinculada à sincronia, na qual uma construção revela diferentes variações de forma ou de função em suas diversificadas intanciações. É o caso, por exemplo, de (8) Quero não, em que o não pós-verbal exibe diferença apenas de forma em relação ao seu uso pré-verbal. O significado, porém, é o mesmo: negar. Outro exemplo de mudança construcional é o que ocorre com (9) Sabe aqueles potinhos de acrílico pra guardar mantimentos?, em que aqueles, mesmo ainda sendo pronome demonstrativo, não é, de fato, um dêitico que aponta para algo fisicamente distante dos parceiros de interação no local em que se encontram. Em vez disso, designa um referente genérico, evocado na memória cultural do interlocutor, sendo, portanto, uma extensão metafórica da construção dêitica central. Em ambos os casos, tais mudanças construcionais manifestam expansão da classe hospedeira da construção, nos termos de Himmelmann (2004), que sanciona construções hierarquicamente subordenadas/de nível inferior (subesquemas ou microconstruções), associadas por links de herança diversos (GOLDBERG, 2006).

4"A difference in syntactic form always spells a difference in meaning." 


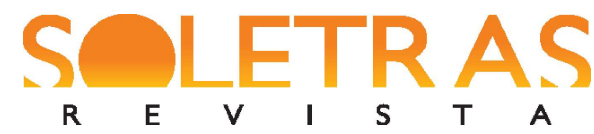

N.37 - 2019.1 - JOSÉ ROMERITO SILVA

Já a construcionalização é um processo gradual, através do tempo, caracterizado por micropassos de mudanças, numa espécie de cline, mais ou menos do tipo $\mathrm{A}>\mathrm{AB}>\mathrm{B}$. Esse processo pode ser observado na seguinte exemplificação com o verbo ir em seu percurso a

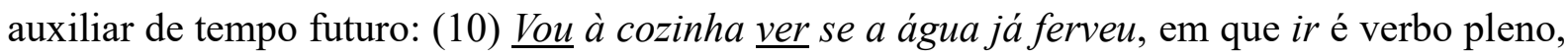
marcando deslocamento espacial; (11) Vou ver se a água já ferveu, no qual parece mesclaremse as noções de deslocamento espacial e ação futura em vou ver; (12) Vou ver o que posso fazer por você, em que vou ver parece exprimir apenas a noção de futuro. Nessa perspectiva, podemos dizer que ir assumiu uma nova função (a de auxiliar) - além da de verbo predicador vinculado à ideia de movimento locativo -, compondo com outro verbo, em posição sintática periférica e dependente, uma nova construção para marcar termpo futuro.

Segundo pesquisadores como Traugott, (2008) e Traugott \& Trousdale (2010), a mudança construcional tem como uma das motivações o mecanismo de analogização. Trata-se de um processo cognitivo no qual se aplica o raciocínio dedutivo, atribuindo-se a um dado exemplar uma ou mais propriedades identificadas em um padrão mais geral, em razão de certa(s) similaridade(s) compartilhada(s) entre um e outro (cf. FISCHER, 2011). Nesse sentido, reproduz-se, de forma paradigmática, um modelo dentro de um certo domínio funcional já ocorrido com outras categorias que compartilham alguma similaridade. Em tal processo, portanto, está implicado o fenômeno de categorização, segundo entendido por autores como Taylor (1995), Bybee \& Hopper (2001), Tomasello (2005), Goldberg (2006).

A esse mecanismo, pode associar-se outro, que Traugott \& Trousdale (2013) denominam "neoanálise". Este tem a ver com a reinterpretação semântica, no plano do conteúdo, e com a reconfiguração morfossintática, no plano da expressão, as quais resultam em alguma alteração na rede construcional. Assim, uma determinada sequência linguística com função específica reconhecida - ou chunk, nas palavras de Bybee (2010) - adquire um novo arranjo sintático/morfológico e uma nova função semântica e/ou pragmática.

No entender de Traugott \& Dasher (2002), além das motivações de caráter linguístico e semântico-cognitivo, as modificações na língua também são favorecidas pelo que os autores denominam "invited inference" [literalmente, inferência convidada], ou, nos termos de Bybee (2010), "pragmatic inference" [inferência pragmática]. Trata-se de um processo intersubjetivo em que o locutor, ao utilizar uma dada expressão linguística com um novo significado em um contexto específico, conta com a colaboração (capacidade de inferenciação) de seu parceiro de interlocução para apreender o sentido desejado. Esse fenômeno, de natureza ao mesmo 


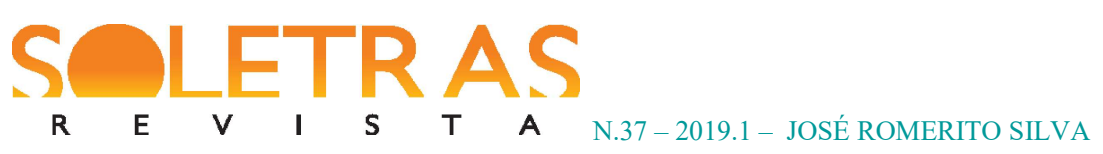

tempo cognitiva e discursivo-interacional, está implicado, portanto, na inovação linguística (que pode levar à mudança de uma construção), quando se dá o uso de uma dada forma linguística em um novo contexto (sintático e discursivo) com significado diverso do convencional. Nessa situação, o falante/escrevente espera que o ouvinte/leitor consiga identificar (ou inferir) a nova função atribuída a essa forma (inovadora ou não) nesse contexto atípico, nos termos de Bergs \& Diewald (2009).

Para ilustrar esses mecanismos aqui, lançamos mão do que ocorre(u), por exemplo, entre as microconstruções graduadoras verbais (13) cansado de tanto esperar> (14) cansado de esperar. No primeiro caso, cansado (adjetivo) é resultado da causa tanto esperar (com o verbo esperar intensificado pelo advérbio tanto); no segundo, esse adjetivo (cansado) parece aglutinar, ao mesmo tempo, tanto a ideia de resultado (mais abstratizado) como a de intensificação do verbo.

Quanto a isso, podemos (pres)supor que o processo de alteração construcional verificado entre (13) e (14) se deu por analogização, uma vez que a forma cansado de esperar incorpora o padrão [[ $\left.\mathrm{X}_{\text {Intens }}\right]$ [de $\left.\left.\mathrm{Y}_{\text {Base }}\right]\right]$, empregado na intensificação de outras categorias,

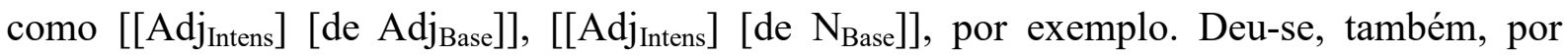
neoanálise, visto que o chunk intensivo cansado de tanto esperar é reagrupado na sequência cansado de [tantø] esperar, dispensando-se o advérbio intensificador convencional (tanto). Assim, tal processo resultou em um novo chunk, no qual o adjetivo é reinterpretado com função intensificadora no lugar do advérbio.

Esse processo reinterpretativo e reorganizador da forma linguística se deve ao jogo negociativo que se estabelece entre os parceiros de interação, de modo que o falante/escrevente promove inovações na língua contando com a capacidade cognitivodiscursiva do ouvinte/leitor em "calcular" o significado pretendido naquele contexto específico. Em outras palavras, é o que Traugott \& Dasher (2002) e Bybee (2010) compreendem como inferenciação pragmática.

\section{Discussão sobre a intensificação verbal}

Almeida (1999), ao abordar a intensificação do verbo, divide este em duas categorias, a saber: "verbos aumentativos" - "os verbos que têm significação encarecida ou exagerada 
para mais" - e "verbos diminutivos" - "os verbos que têm significação encarecida ou exagerada para menos" (p. 302-303). O autor sublinha, ainda, que esses verbos são formados, em geral, pelos processos de prefixação e/ou de sufixação.

Almeida cita exemplos como bravejar <esbravejar, fulgir < refulgir, jurar <tresjurar, picar <espicaçar, roer <corroer, soar < ressoar, torcer <retorcer, entre outros, para os aumentativos. No caso dos diminutivos, apresenta verbos como adoçar >adocicar, beber $>$ bebericar, chorar >choramingar, dormir >dormitar, ferver $>$ fervilhar, lamber $>$ lambiscar, saltar $>$ saltitar e outros mais.

Lopes (2003), por sua vez, tratando do grau do verbo, afirma que este é intensivo por natureza quando tal intensificação se inscreve no próprio lexema, sem precisar sofrer nenhum processo de conversão ou metaforização. Para o autor, nesse aspecto, os verbos dividem-se em graduáveis (dimensivos ou qualitativos) e absolutos.

Os verbos graduáveis expressam uma visão relativa do locutor, os quais possibilitam a intensidade numa escala gradativa. Quanto aos verbos graduáveis dimensivos, o autor menciona exemplos como aumentar, diminuir e outros. Já os graduáveis qualitativos exprimem intensidade em termos mais avaliativos. Lopes cita, por exemplo, verbos como melhorar, piorar, entre outros (p. 102). Em relação aos verbos absolutos, esclarece que estes exprimem um grau extremo, expressando intensificação enfática, que extrapola os limites da própria escala. Para exemplificá-los, o autor cita casos como esmerar-se, arrombar, horrorizar-se, além de outros (p. 103).

Silva (2008), ao abordar o grau do verbo, mostra que este é tão produtivo e recorrente quanto o que se dá com substantivos, adjetivos e advérbios. Examinando dados reais de fala e de escrita, identifica que o verbo pode denotar intensidade no próprio lexema, como é o caso de odiar; pela afixação, tal como espicaçar; por meios sintáticos diversos, como se vê em gosto muito, cansado de esperar; chora, chora, chora; e até por recursos fonéticos suprassegmentais, como em aMEEEEiii. A título de amostragem, seguem abaixo exemplares de alguns desses casos:

(1) Parabéns Dani por o trabalho maravilhoso e por o carinho com nós! Mil beijos..... daniiiiiiiiiii amo demais suas dicas! são as melhores, de verdade.. super me inspiro e aprendo prá caramba sobre o mundo dos esmaltes e cia! haahahahah adoroooooooooooooo muito sucesso 


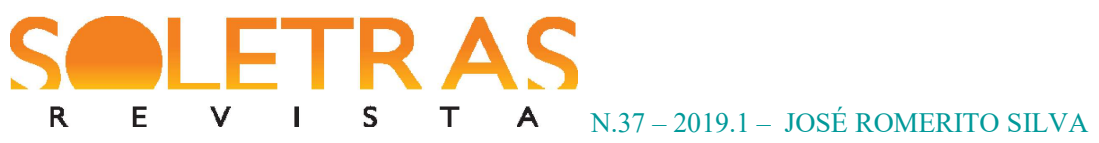

sempre! $!^{5}$ (Disponível em: <http://unhabonita.com.br/esmalte-durar-mais/. Fonte: http://www.corpusdoportugues.org/web-dial/>. Acesso em: 20 nov. 2017.)

Nesse recorte textual, podemos identificar algumas intensificações verbais, predominantemente pelo modo sintático, em que um elemento intensivo (advérbio ou expressão adverbial) modifica o verbo, graduando-o. Entre elas, destacamos amo demais e aprendo prá caramba. Há também outra forma de graduação do verbo, a qual se dá por meio do alongamento silábico, em adoroooooooooooooo.

Entretanto, o que tem chamado a atenção ultimamente são usos de verbos intensificados por super, estando este em condição semelhante ao advérbio de intensidade, tal como se vê, nesse mesmo recorte textual, com a construção super me inspiro. Trata-se de uma forma inovadora de intensificação de verbos por meio de um recurso sintático incomum pelo menos, até pouco tempo -, no PB, para essa categoria lexical. Essa inovação é bem recente, não sendo encontrada, pelo visto, até o fim do século passado e o início deste, conforme varredura feita em registros de fala e de escrita nos corpora disponíveis. Para confirmação, vejamos mais estas ocorrências:

(2) Meninas super vale a pena conhecer essa pequena cidade que em a verdade parece um "Brás das porcelanas e MDF"... Comprei xicaras de porcelana por 2 reais, Bule de porcelana branca por 6 reais... A D O R E I! \&Super recomendo!

(Disponível em: <http://casandosemgrana.com.br/feira-de-artesanato-pedreirasp/[29/03/2013]>. Acesso em: 20 nov. 2017.$)$

(3) [...] amei sua pagina, super me identifiquei. que Deus abençoe seu trabalho. pois é cada vez mais raro encontrar jovens que estejam dispostos a pregar o envangelho [...]

(Disponível em: < http://profetadeallstar.tumblr.com/post/128493148190/oiee-amei-sua-pagina-super-me-identifiquei>. Acesso em: 20 nov.

(4) Lugar perfeito! Super quero voltar!

(Disponível em: <http:/www.booking.com/reviews/br/hotel/mata-atlac-ntica-park/review/67dbe64bae96959f.pt-br.html>. Acesso em: 20 nov. 2017.)

Retomando a primeira pergunta - quais as distinções entre o novo padrão de intensificação verbal com super e o que tem esse intensificador como prefixo? -, podemos verificar, pelas amostras 2, 3 e 4, que esses recursos de intensificação do verbo com super diferem do formato derivacional por prefixação já convencionalizado, tal como se observa,

5Optamos por iniciar nova numeração das amostras do corpus selecionadas para análise. 


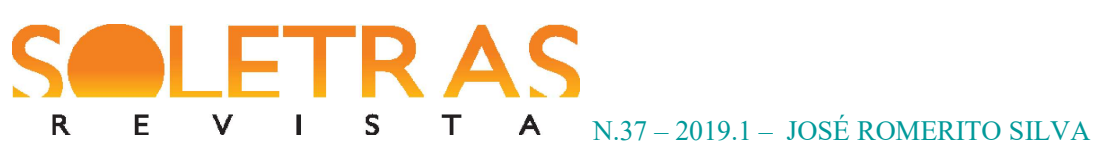

por exemplo, em supervalorizar. Este último resulta de um processo normal de formação lexical no português, também equivalente a casos como ultrapassar, sobrepujar, transportar, entre outros. Nesses casos, o verbo resultante do processo pode ser conjugado nos diferentes tempos e modos bem como ter flexão número-pessoal diversa.

Contudo, em casos como 2, 3 e 4, o verbo com super não se conjuga em todos os tempos e modos (entre eles o imperativo) tampouco se flexiona na $2^{\mathrm{a}}$ pessoa. Voltando aos verbos das amostras dadas, soariam demasiadamente estranhas, por exemplo, expressões do tipo *Super valha a pena; *Super recomendem; ou mesmo *Super nos identifiquemos; *super queiramos voltar.

Além dessas diferenças de uso entre as formas convencionais de verbos com super e a nova construção de intensidade do verbo por meio desse item, devem ser considerados, ainda, o comportamento e o estatuto morfossintático deste. No primeiro caso, super atua como prefixo formador de palavras; portanto, é uma forma presa, compondo com a base verbal um todo lexical. No segundo, não é possível manter super como prefixo. Diferentemente disso, comporta-se de maneira semelhante a um advérbio de intensidade, podendo, desse modo, ser considerado uma forma dependente em relação ao termo (item ou expressão verbal) a que se vincula, particularmente em construtos como super vale a pena (em 1) e super me identifiquei (em 2). Assim, embora super funcione como intensificador tanto nos usos convencionais como nos mais recentes, em ambos os casos, esse elemento tem condição morfossintática diversa.

Com base nessas constatações, na linha de Traugott \& Trousdale (2013) e de Traugott (2009), concluímos que existem duas microconstruções distintas de intensificação do verbo com super: uma proveniente da formação lexical de um verbo com o prefixo super, que tem como paradigma o padrão $\left[\left[\right.\right.$ Pref $\left.\left._{\text {Intens }}\right]\left[\mathrm{V}_{\text {Base }}\right]\right]$ e outra que tem como referência o modelo $\left[\left[\mathrm{Adv}_{\text {Intens }}\right]\left[\mathrm{V}_{\text {Base }}\right]\right]$. Ambas vinculam-se ao subesquema - ou mesoconstrução - [[ $\left.\mathrm{X}_{\text {Intens }}\right]$ $\left.\left[\mathrm{V}_{\mathrm{Base}}\right]\right]$, o qual, por sua vez, é uma instanciação do esquema genérico - ou macroconstrução $\left[\left[\mathrm{X}_{\text {Grau }}\right]\left[\mathrm{Y}_{\text {Base }}\right]\right]$. Sob tal perspectiva, podemos afirmar que essas microconstruções intensivas são esquemáticas, uma vez que, nas instanciações verbais com super, está pressuposto/ implicado um modelo paradigmático de formulação da ideia de grau entre uma forma intensificadora e outra intensificada. As relações hierárquicas entre essas microconstruções verbais podem ser representadas na rede construcional a seguir. 


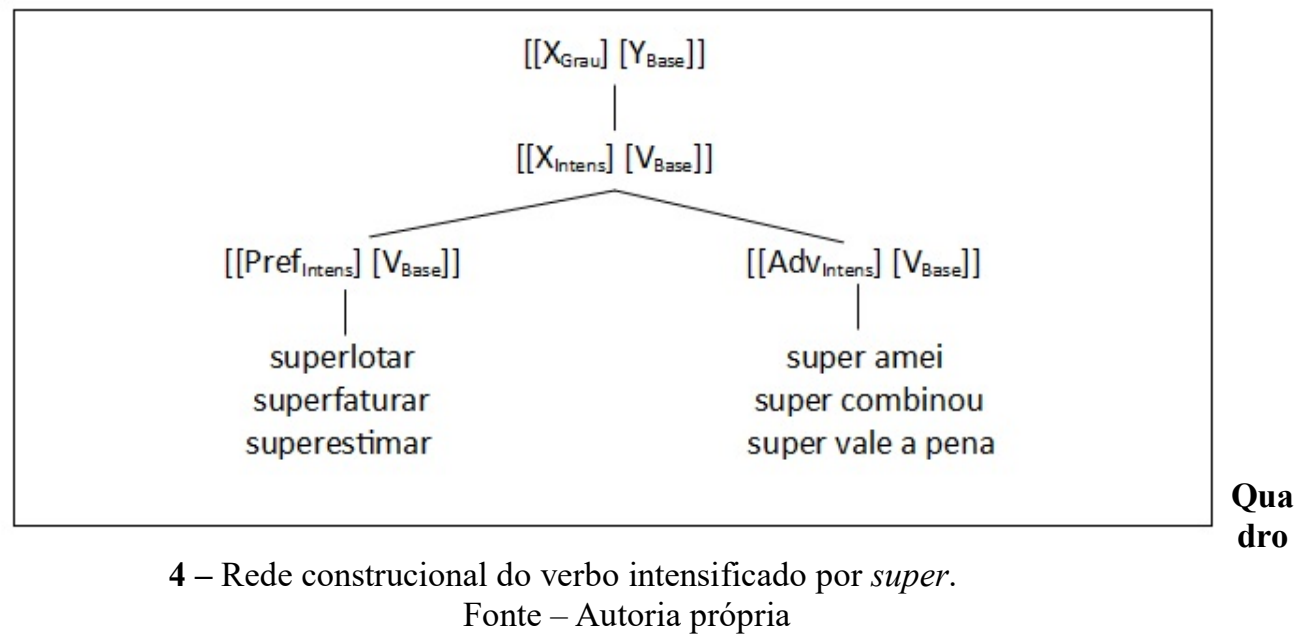

Cabe assinalar, entretanto, que, considerada sob a perspectiva do elemento intesificador - super -, as microconstruções intensivas com esse elemento, na condição de prefixo ou de advérbio, seriam consideradas parcialmente especificadas. Isso pelo fato de super pertencer ao slot já preenchido (invariante) da construção e o verbo representar o slot a ser preenchido, a depender do type verbal, conforme esboçamos a seguir: [[SuperPref Intens] $\left.\left[\mathrm{V}_{\text {base }}\right]\right] /\left[\left[\right.\right.$ Super $\left.\left._{\text {Adv Intens }}\right]\left[\mathrm{V}_{\text {base }}\right]\right]$.

No que diz respeito à segunda pergunta - como se configura a construção de intensidade verbal com super em termos semânticos, sintáticos e morfológicos? -, podemos observar o que segue: foram identificados no corpus cinco (5) types (ou categorias) de verbos, a saber, transitivo direto (VTD), transitivo relativo (VTR), ditransitivo (VDit), transitivo indireto (VTI) e intransitivo (VInt). Ilustramos cada um desses types, na ordem em que se encontram,com as seguintes amostras:

(5) Eu super abracei a causa, tenho um carinho imenso pela personagem e pela Drica", contou Marjorie em entrevista a reportagem, logo após participar do Bate-Papo UOL, nesta sexta-feira (12).

(Disponível em: <http://televisao.uol.com.br/noticias/redacao/2014/12/12/super-abracei-a-causa-diz-marjorie-estiano-sobre-seu-retorno-aimperio.htm>. Acesso em: 20 nov. 2017.)

(6) Não sou muito fã de Lacan, mas super concordo com isso! Graças a Deus que somos feitos de incompletude $[\ldots]$

(Disponível em: <http://freethoughts-ipk.tumblr.com/post/55816281469/n\%C3\%A3o-sou-muito-f\%C3\%A3-de-lacan-mas-super-concordocom>. Acesso em: 20 nov. 2017.)

(7) AMEIII o post beijos Tenho a Electrolux Eco Turbo $9 \mathrm{~kg}$ certamente foi uma das melhores 


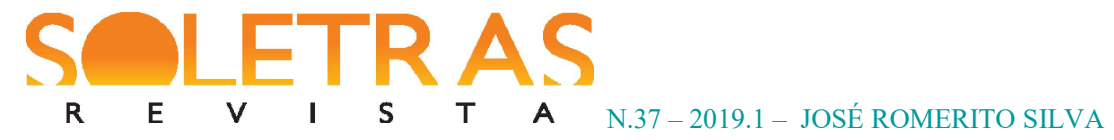

aquisições que fizemos para o nosso ap, ela é sensacional! Super indico:) [...]

(Disponível em: <http://www.comprandomeuape.com/2013/05/lava-e-seca-para-lavanderia-do-meu-ape.html. Fonte: http://www.corpusdoportugues.org/web-dial/>. Acesso em: 20 nov. 2017.)

(8) "Um cara que comanda uma corporação acaba falando de vários outros da vida real, e isso super me interessa", diz, referindo-se a 3\%, que estreia este ano.

(Disponível em: <http://atarde.uol.com.br/muito/noticias/1760551-tempo-em-movimento>. Acesso em: 20 nov. 2017.)

(9) Instalei normalmente, super funcionou, por 5 minutos! Ao atualizar o antivírus foi pedido a reinicialização, pronto agora não aparece nada na tela, [...]

(Disponível em: < https://answers.microsoft.com/pt-br/windows/forum/windows_10-update/atualiza\%C3\%A7\%C3\% A3o-do-windows-10deu-errado/c2ba6244-eb1c-4f10-983a-dcb95908ad13?auth=1>. Acesso em: 20 nov. 2017.)

Em relação a essas categorias verbais, observamos que a predominância é de verbos pertencentes ao type VTD. Essa observação pode ser comprovada pelo seguinte levantamento quantitativo: das 33 instâncias de verbos colhidos - no total de 37 ocorrências das 30 amostras textuais -, $22(67 \%)$ são VTD. Os demais types distribuem-se conforme os resultados que seguem: 05 verbos (15\%) pertencem ao type VTR; 03 (9\%), ao VDit; e os das categorias VTI e VInt respondem por 02 (6\%) e 01 (3\%), respectivamente.

Ainda no tocante a esses types verbais, constatamos que os VTD, em termos semânticos, caracterizam-se, principalmente, por serem de conteúdo cognitivo-afetivo ou volitivo. Isso se mostra, por exemplo, em verbos como compreender, querer, aceitar, aprovar, amar, curtir, respeitar, entre outros. Conforme se pode ver, esses verbos, em sua maioria, estão mais vinculados a sujeitos cujos traços semânticos são humano e volitivo, embora tais sujeitos não possam ser, de fato, considerados agentivos em razão da natureza dos verbos, que se relacionam mais a processos/experiências subjetivo(a)s.

Nesse sentido, os complementos-objetos associados a esses verbos são não-afetados. Além disso, cabe frisar, com base nos dados, que esses complementos se distribuem, de forma relativamente equilibrada, entre os traços humano e não-humano. Vejamos estas ocorrências, que exemplificam tais afirmações:

(10) [...] gente do grupo Blogosfera, Instagram e Facebook, super me apoiam e isso me deixa feliz. Mas ainda falta alguma coisa.

(Disponível em: < http://semneurasemproblema.blogspot.com.br/2013/03/o-que-falta.html[10/03/2013].Fonte: http://www.corpusdoportugues.org/web-dial/>. Acesso: 20 nov. 2017.)

(11) Doutor falou "pé pra cima!" e eu super respeitei sua decisão! Ou tentei na maior parte do tempo 


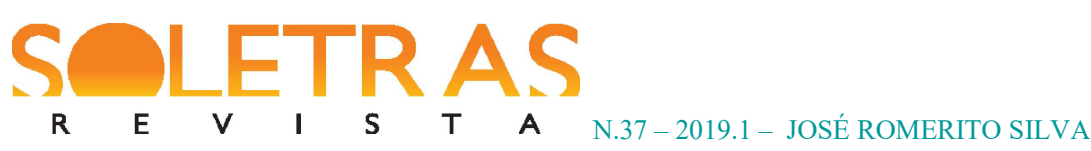

né?

(Disponível em: <https://www.instagram.com/p/BASxYlXg_p4/>. Acesso: 20 nov. 2017.)

Conforme demonstram essas ocorrências, os complementos me (em 10) e sua decisão (em 11), os quais se associam, respectivamente, aos verbos apoiar e respeitar, são nãoafetados, posto que esses verbos, embora se relacionem a sujeitos volitivos, não designam ações destes, e sim processos cognitivo-afetivos que não causam mudança direta/perceptível nos objetos-recipientes beneficiários. Destacamos, ainda, o fato de, em 10, o objeto ter o traço humano e, em 11, não-humano, apenas para ilustrar o equilíbrio observado nos dados do corpus quanto a essas propriedades dos complementos dos verbos sob enfoque.

Quanto ao levantamento exposto anteriormente, verificamos que a maioria dos verbos intensificados participa da estrutura sintática do enunciado na sequência prototípica do português, isto é, Sujeito-Verbo-Complemento(s) - SVComp. Nos casos de omissão do objeto, este pode ser recuperado do cotexto antecedente. Vejamos as amostras a seguir:

(12) Me aceita aqui eu super considero ela como a minha sogra.

(Disponível em: $<$ https://www.facebook.com/permalink.php?story_fbid=573772979373353\&id= 504045319679453>. Acesso em: 20 nov.

(13) Achei que essa maquiagem super combinou com o batom da Magia das Fadas.

(Disponível em: <https://www.facebook.com/JuBalduinomakeup/photos/>. Acesso em: 20 nov. 2017.)

(14) [...] super amei os tempeiros. super indico para meus amigos e familiares parabéns a maggi por esse sabor fantástico com gostinho de quero mais e deixando minhas receitas muito mais deliciosas :) (Disponível em: <https://www.bzzagent.com/pc/maggi-natusabor/gallery/item/chegou-super-amei-os-tempeiros>. Acesso em: 20 nov. 2017.)

(15) A maioria das pessoas hoje têm as fotos no computador ou no celular. O álbum é o álbum do Facebook ou do Instagram. Eu acho legal também, e super compartilho.

(Disponível em: <https://abilolando.com/tag/decoracao-com-fotos/>. Acesso em: 20 nov. 2017.)

Nas ocorrências 12 e 13, vemos que a estrutura argumental dos verbos intensificados, que são TD, se encontra na sequência prototípica SVComp, com os respectivos argumentos eu e ela (em 12) e essa maquiagem e com o batom da Magia das Fadas (em 13). Nas amostras 14 e 15, verificamos que super indico (em 14) e super compartilho (em 15) estão sem seus respectivos complementos, ou argumentos internos: os tempeiros [sic], no primeiro caso,e as fotos, no segundo. Esse apagamento se deve ao fato de estes terem sido anteriormente citados, o que permite recuperá-los facilmente no cotexto; daí, as anáforas zero. 
Do ponto de vista morfológico, os verbos intensificados por super se flexionam, majoritariamente, no presente ou no pretérito perfeito do indicativo e na $1^{\mathrm{a}}$ ou na $3^{\mathrm{a}}$ pessoa do singular. Para comprovar essa afirmação, vejamos os dados: quanto ao tempo verbal, das 37 ocorrências, 24 delas (65\%) estão no presente do indicativo e as demais (35\%), no pretérito perfeito; quanto à pessoa, 21 amostras $(57 \%)$ estão na $1^{\mathrm{a}}$ pessoa do singular, $14(38 \%)$ na $3^{\mathrm{a}}$ do singular e apenas $02(5 \%)$ na $3^{\text {a }}$ do plural. Podemos exemplificar isso com as amostras que seguem:

(16) Legal cara. Não sou Mórmon, mas sou cristão protestante. Super apóio essa parada, pq antes de tudo, Cristo $[\ldots]$

(Disponível em: <https://plus.google.com/+LukasGasparotto/posts/dpnKJkU4e2H>. Acesso: 20 nov. 2017.)

(17) Super curti essa cabeceira de cama feita com fitas adesivas, sem falar dessas almofadas, dessa luminária customizada, dessas flores [...]

(Disponível em: <http://www.decora.me/i/55eb74a3>. Acesso: 20 nov. 2017.)

(18) Casinha que super agrada com arranjo de rosas, ursinho de pelúcia mais caixa de bombons [...]

(Disponível em: < https://www.florestaonline.net/casinha-super-agrada>. Acesso: 20 nov. 2017.)

(19) Instalei normalmente, super funcionou, por 5 minutos! Ao atualizar o antivírus foi pedido a reinicialização, pronto agora não aparece nada na tela, [...]

(Disponível em: <https://answers.microsoft.com/pt-br/windows/forum/windows_10-update/atualiza\%C3\%A7\%C3\% A3o-do-windows-10deu-errado/c2ba6244-eb1c-4f10-983a-dcb95908ad13?auth=1>. Acesso em: 20 nov. 2017.)

Nas amostras 16 e 17, as respectivas formas verbais apóio e curti estão na $1^{\text {a }}$ pessoa do singular, sendo que, em 16, o verbo está no presente do indicativo e, em 17, no pretérito perfeito. Nas ocorrências 18 e 19, do mesmo modo, agrada e funcionou encontram-se na $3^{\mathrm{a}}$ pessoa do singular, estando a primeira no presente do indicativo e a segunda no pretérito perfeito.

Considerando a terceira questão - por que esse novo padrão de intensificação do verbo [com super]deve ser visto como um caso de mudança construcional? -, assumimos, ancorados em Traugott \& Trousdale (2013), que se trata de um caso de mudança construcional pelo fato de haver alteração construcional apenas no plano da forma. Nessa perspectiva, o verbo se relaciona com o intensificador super, porém este não mais atua na condição de prefixo (morfema preso) formador de palavra, e sim na de advérbio (item dependente). Entretanto, conforme já explicitado, seja como prefixo ou como advérbio, a 


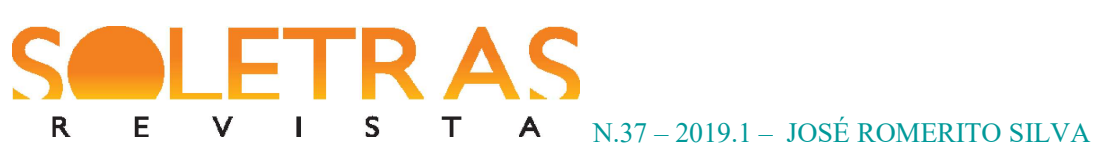

função semântica de super permanece a mesma, isto é, intensificar o elemento a que se vincula, no caso, o verbo.

Em vista disso, confirma-se o fato de que se trata do fenômeno de mudança construcional, posto que, comparando-se a microconstrução verbal com super mais recente com a convencional, temos novidade de forma ([[Pref] $[\mathrm{V}]]>[[\mathrm{Adv}][\mathrm{V}]])$, mas permanência de conteúdo semântico ([[Intens] [Base]]). Segundo Traugott \& Trousdale (2013), quando ocorre modificação construcional tão somente em um dos polos da construção, não resultando em um novo pareamento de forma e função (isto é, em um novo nó na rede, nova construção), configura-se, portanto, o que os autores denominam mudança construcional (ver Quadro 3, p. 6).

A respeito desse fenômeno de mudança formal mas de "conservação" funcional, a tradição funcionalista, na linha de Bolinger ([1968] apud GOLDBERG, 1995), Haiman (1983) e de Givón (1985), defende que alguma alteração de forma indicia relativa (ou mesmo absoluta) diferença na função, seja semântica e/ou pragmática. Coerente com essa premissa, o princípio da não-sinonímia, formulado por Goldberg (1995), desenvolve raciocínio equivalente em relação à similaridade/divergência formal entre construções.

Voltando ao caso da mudança construcional, com base nessa linha de pensamento, verificamos que ambas as microconstruções de intensificação do verbo com super no PB atual, embora apresentem semelhança de conteúdo semântico, além de serem formalmente díspares, parecem também divergir no que se refere ao uso (ou função pragmática). Isso se revela no fato de a microconstrução de verbo com super como prefixo (super Pref $_{-}$a exemplo de superlotar, superfaturar e outros) poder ser utilizada em contextos variados de fala e de escrita, enquanto a nova microconstrução com super como advérbio $\left(\right.$ super $_{A d v}$ ) parece, ao menos no momento, circunscrever-se a situações de fala e de escrita mais distensos, de baixo monitoramento formal, em razão do forte teor de (inter)subjetividade que caracteriza a produção discursiva em que ocorrem.

Como se trata de textos colhidos de posts da web, publicados, principalmente, em blogs e em redes sociais, tais textos estão mais associados à oralidade, na acepção de Koch \& Oesterreicher (2013). Assim, a constatação da equivalência semântica e das disparidades formal e pragmática entre ambas as microconstruções verbais com super é compatível com as postulações de Bolinger e de Goldberg, explicitadas anteriormente, sobre a não-sinonímia absoluta da estrutura linguística. 
Por fim, trazendo de volta a ultima questão deste artigo - que fator(es) está(ão) implicado(s) no recrutamento de super para a formação desse novo padrão de intensificação verbal? -, defendemos que a emergência da nova microconstrução de intensidade do verbo com super como advérbio deve ter sido favorecida pelo mecanismo de analogização, tal como esta é entendida por Traugott (2008), Bybee (2010), Traugott \& Trousdale (2010) e Fischer (2011). Essa afirmação é plausível, considerando-se que, nesse caso, dá-se a reprodução de um modelo do mesmo domínio funcional, já ocorrido com outras categorias, em que super comporta-se como advérbio (Ex.: super + Adv - passou super devagar, dormir super tarde; super + SP - estava super a fim, ficou super sem graça; super + composto - foi super maleducado, somos super bem casados).

Em vista disso, podemos dizer, alinhados com Himmelmann (2004), que houve expansão da classe hospedeira na rede da construção intensiva. Tal expansão se explica, de um lado, pelo fato de o verbo ser intensificado por super, estando este na condição de advérbio anteposto, posição comum para esse intensificador, mas inovadora em se tratando de verbo, já que este, convencionalmente, se intensifica por um(a) advérbio/locução adverbial a ele posposto(a). Por outro lado, explica-se porque super $_{A d v}$ intensivo amplia seu leque de categoria por ele modificada - no caso, o verbo -, tal como já ocorrera com outras categorias, conforme demonstramos no parágrafo anterior. Nesse caso, o slot de itens modificados por super, antes preenchido apenas por adjetivos e substantivos, passa a ser também ocupado por determinados verbos, além de certos advérbios, SP e compostos, que podem ser modificados por esse intensificador.

De acordo com Goldberg (1995), Bybee (2010), Traugott \& Trousdale (2013), esse fenômeno de expansão da classe hospedeira associa-se ao processo de generalização. Este ocorre em razão de um dado padrão (sub)esquemático passar a ser comunicativamente eficaz e mais frequente, com forte tendência a se estender, pelo sancionamento de outras categorias, tornando-se modelo paradigmático para a emergência/formulação de novos (sub)types construcionais.

\section{Considerações finais}

Neste artigo, examinamos, em particular, a construção de intensidade verbal com 


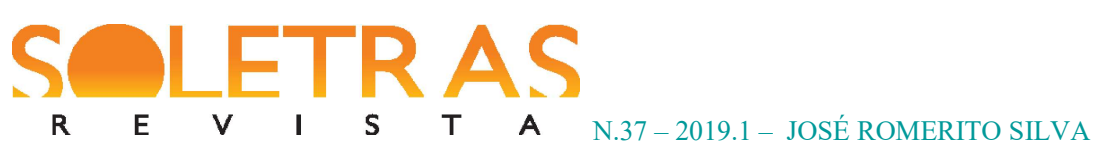

super $_{A d v}$. A esse respeito, vimos que se trata, na verdade, de uma microconstrução, na qual o componente intensificador (super) assume status adverbial. Sendo assim, distingue-se de sua "co-irmã", mais convencional, em que super atua como prefixo formador de palavra. Nessa perspectiva, seguindo Goldberg (1995) e Traugott \& Trousdale (2013), concluímos que ambas as microconstruções vinculam-se, por instanciação, ao subesquema superordenado [[ $\left.\mathrm{X}_{\text {Intens }}\right]$ $\left.\left[\mathrm{V}_{\mathrm{Base}}\right]\right]$, sendo este sancionado pelo esquema genérico $\left[\left[\mathrm{X}_{\mathrm{Grau}}\right]\left[\mathrm{Y}_{\mathrm{Base}}\right]\right]$.

Quanto aos verbos intensificados por super $_{A d v}$, verificamos, conforme levantamento quantitativo, que são, em sua maioria, transitivos, predominando os do type VTD. Em relação a isso, constatamos, também, que tais verbos são de conteúdo cognitivo-afetivo, mais vinculados a sujeitos com os traços humano, volitivo, não-agentivo. Desse modo, os complementos-objetos desses verbos são não-afetados. Ainda sobre os verbos analisados, assinalamos, apoiados no levantamento feito, o fato de eles serem usados, principalmente, nos tempos presente e pretérito perfeito do indicativo, na $1^{\mathrm{a}}$ ou na $3^{\mathrm{a}}$ pessoa do singular. A propósito, esse é um dos motivos da distinção entre a nova microconstrução e a que tem super como prefixo: nesta, o verbo pode ser, indiferentemente, flexionado nos mais variados tempos, modos e pessoas, possibilidade não aplicável àquela.

Neste trabalho, defendemos que esse recente modo de intensificação do verbo no PB revela um caso de mudança construcional. Tomamos como base para isso o que postulam Traugott \& Trousdale (2013), segundo os quais esse fenômeno associa-se a uma modificação interna a uma construção, ocorrida no plano da forma ou no da função. Nesse sentido, constatamos que, na microconstrução sob enfoque, a alteração se mostra em sua configuração formal, com preservação do conteúdo semântico. Todavia, coerente com o princípio da nãosinonímia, formulado por Goldberg (1995), conquanto haja permanência do significado intensivo na nova forma verbal modificada por $\operatorname{super}_{A d v}$, seu uso parece restringir-se a contextos mais relacionados à informalidade e à (inter)subjetividade discursivas, os quais são marcados pelo baixo monitoramento do locutor e, por isso, mais próximos da oralidade. Sendo assim, além de especificidades morfo-sintáticas, essa microconstrução também difere

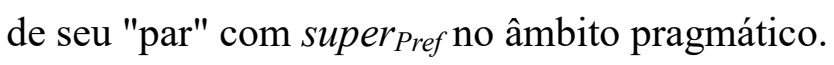

No tocante aos fatores subjacentes à emergência da microconstrução aqui examinada, entendemos que esse fenômeno envolve(u) motivações cognitivas e sociodiscursivas. Entre esses fatores, apontamos, em especial, os mecanismos de analogização e de generalização, na linha de Traugott (2008), de Bybee (2010) e de Fischer (2011). O primeiro tem a ver com a 


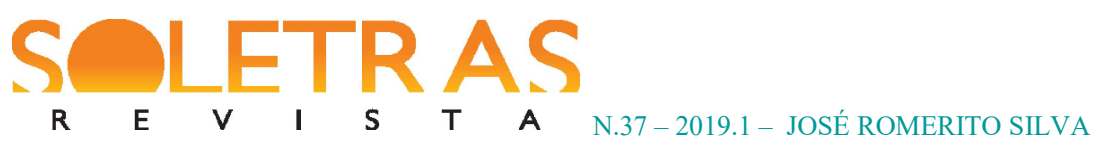

reprodução de um modelo em um domínio funcional, a partir do estabelecimento de determinadas associações, em razão da existência de alguma similaridade de forma ou de função entre construções. A eficiência desse modelo leva à incorporação de novas categorias, ou expansão da classe hospedeira, conforme Himmelmann (2004). Nesse viés, o fato de já haver algumas categorias intensificadas por super ${ }_{A d v}$, com certa frequência de uso em contextos mais distensos/informais, pode ser apontado como atrator para a entrada de verbos nesse modelo, o que sinaliza a generalização desse paradigma. Acrescentamos, ainda, a esses mecanismos o processo de inferenciação pragmática estabelecido entre os parceiros de interação, o qual, para Traugott \& Dasher (2002) e Bybee (2010), entre outros, desempenha papel crucial na inovação/mudança linguística.

\section{Referências}

ALMEIDA, Napoleão M. de. Gramática metódica da língua portuguesa. 43. ed. São Paulo: Saraiva, 1999.

BERGS, Alexander; DIEWALD, Gabriele. (Eds.). Contexts and constructions. Amsterdam; Philadelphia: John Benjamins, 2009.

BYBEE, Joan. Language, usage and cognition. Cambridge: Cambridge University Press, 2010 .

BYBEE, Joan; HOPPER, Paul J. (Eds.). Frequency and the emergence of linguistic structure. Amsterdam; Philadelphia: John Benjamins, 2001.

CROFT, William. Radical construction grammar: syntactic theory in typological perspective. Oxford: Oxford University Press, 2001.

FISCHER, Olga. Grammaticalization as analogically driven change? In: NARROG, Heiko; HEINE, Bernd (Eds.). The Oxford handbook of grammaticalization. Oxford: Oxford University Press, 2011, p. 31-42.

FRIED, Mirjam. Construction grammar. In: KISS, Tibor; ALEXIADOU, Artemis (Eds.). Syntax - theory and analysis: an international handbook, v. 1. Handbooks of Linguistics and Communication Science. Berlin: Mouton de Gruyter, 2015, p. 974-1003.

FURTADO DA CUNHA, Maria Angélica; BISPO, Edvaldo B.; SILVA, José Romerito. Linguística Funcional Centrada no Uso: conceitos básicos e categorias analíticas. In: CEZARIO, Maria Maura; FURTADO DA CUNHA, Maria Angélica. (Orgs). Linguística Centrada no Uso: uma homenagem a Mário Martelotta. Rio de Janeiro: Mauad; FAPERJ, 


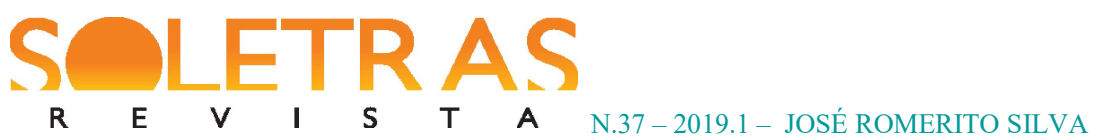

2013.

FURTADO DA CUNHA, Maria Angélica; SILVA, José Romerito; BISPO, Edvaldo B. O pareamento forma-função nas construções: questões teóricas e operacionais. Revista LinguíStica - Revista do Programa de Pós-Graduação em Linguística da UFRJ. vol. Especial, dez. de 2016, p. 55-67.

GIVÓN, Talmy. Iconicity, isomorphism, and non-arbitrary coding in syntax. In: HAIMAN, John (Ed.). Iconicity in syntax: proceedings of a symposium on iconicity in syntax. Amsterdam; Philadelphia: John Benjamins, 1985, p. 187-220.

GOLDBERG, Adele E. A construction grammar approach to argument structure. Chicago: The University of Chicago Press, 1995.

GOLDBERG, Adele E. Constructions: a new theoretical approach to language. TRENDS in Cognitive Sciences, v. 7, n. 5, p. 219-224, 2003.

GOLDBERG, Adele E. Constructions at work: the nature of generalization in language. Oxford: Oxford University Press, 2006.

HAIMAN, John. Iconic and economic motivation. Language. v. 59, n. 4, p. 781-819, 1983.

HIMMELMANN, Nikolaus P. Lexicalization and grammaticization: opposite or orthogonal? In: BISANG, Walter; HIMMELMANN, Nikolaus P.; WIEMER, BJÖRN. (Eds.). What makes grammaticalization?: a look from its fringes and its components. Berlin; New York: Mouton de Gruyter, 2004, p. 21-42.

KEMMER, Suzanne; BARLOW, Michael. Introduction: a usage-based conception of language. In: BARLOW, Michael; KEMMER, Suzanne. (Eds.). Usage-based models of language. Stanford: Center for the Study of Language and Information, 2002, p. vii-xxviii.

KOCH, Peter; OESTERREICHER, Wulf. Linguagem da imediatez - linguagem da distância: oralidade e escrituralidade entre a teoria da linguagem e a história da língua. Trad. Hudinilson Urbano e Raoni Caldas. Linha d'Água, n. 26 (1), p. 153-174, 2013.

LOPES, Carlos Alberto G. Lexemas verbais operadores da intensidade. In: Cadernos do VII CNFL: Discurso e Língua Falada. Rio de Janeiro: CiFEFiL, 2003, p. 102-110.

SILVA, José Romerito. Variações de "super" no português do Brasil. In: PASSEGGI, Luis S.; OLIVEIRA, Maria do Socorro (Orgs.). Linguística e educação: gramática, discurso e ensino. São Paulo: Terceira Margem, 2001, p. 111-127.

SILVA, José Romerito. Motivações semântico-cognitivas e discursivo-pragmáticas nos processos de intensificação. Tese de Doutorado. Natal, RN: PPgEL/UFRN, 2008.

SILVA, José Romerito. O grau em perspectiva: uma abordagem centrada no uso. São Paulo: Cortez, 2015. 


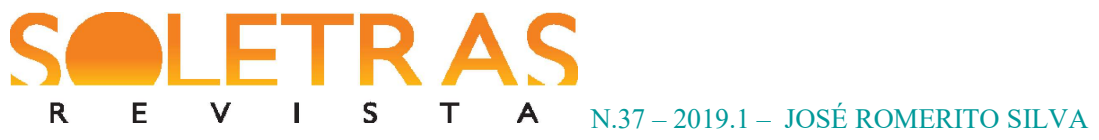

TAYLOR, John R. Linguistic categorization: prototypes in linguistic theory. 2. ed. Oxford: Clarendon Press, 1995.

TOMASELLO, Michael. Constructing a language: a usage-based theory of language acquisition. Cambridge; London: Harvard University Press, 2005.

TRAUGOTT, Elizabeth C. "All that he endeavoured to prove was...": on the emergence of grammatical constructions in dialogual and dialogic contexts. COOPER, Robin; KEMPSON, Ruth. (Eds.). Language in flux: dialogue coordination, language variation, change and evolution. London: Kings College Publications, p. 143-177, 2008.

TRAUGOTT, Elizabeth C. Grammaticalization and Construction Grammar. In: CASTILHO, Ataliba T. de. (Org.). História do português paulista. v. 1. Campinas: Publicações IEL, 2009, p. 91-101.

TRAUGOTT, Elizabeth C; DASHER, Richard B. Regularity in semantic change. Cambridge: Cambridge University Press, 2002.

TRAUGOTT, Elizabeth C; TROUSDALE, Graeme. Gradience, gradualness and grammaticalization: how do they intersect? In: TRAUGOTT, Elizabeth C; TROUSDALE, Graeme. (Eds.). Gradience, gradualness and grammaticalization. Amsterdam; Philadelphia: John Benjamins, 2010, p. 19-44.

TRAUGOTT, Elizabeth C; TROUSDALE, Graeme. Constructionalization and constructional changes. New York: Oxford University Press, 2013.

\title{
Verb intensification and constructional change
}

\begin{abstract}
In this paper, we have as central focus the intensification of verbs using super. We adopt the hypothesis that it reflects a constructional change phenomenon. Our aim is to show that this new way of intensifying verbs differs from the conventional one - in which super takes part in the lexical formation of the verb as a prefix - resulting in a new microconstruction in contemporary Brazilian Portuguese. To do that, we follow theoretical and methodological assumptions of the Usage-based Functional Linguistics approach. Oral and written texts from different genres are used as database. Preliminary investigation suggests that forms of verbs intensified by super seem to be still restricted to contexts of spontaneous speech, more closely related to less controlled orality.
\end{abstract}

Keywords: Verb intensification. Usage-based Functional Linguistics. Constructional change.

Recebido em: 21 de outubro de 2018.

Aceito em: 20 de março de 2019. 